\title{
Prophylactic clipping and post-polypectomy bleeding: a meta- analysis and systematic review
}

\author{
Christine Boumitria, Fazia A. Mira, Imran Ashrafa, Michelle L. Matteson-Kome ${ }^{a}$, Douglas L. Nguyen ${ }^{\text {, }}$ \\ Srinivas R. Pulic, Matthew L. Bechtold ${ }^{a}$
}

University of Missouri, Columbia; University of California, Irvine; University of Illinois, Peoria, USA

\section{Abstract}

\section{Introduction}

Colorectal cancer is a common cancer in the United States, being the second leading cause of cancer death when genders are combined [1]. In 2016, the estimated number of new cases of

Departments of ${ }^{a}$ Medicine, University of Missouri, Columbia (Christine Boumitri, Fazia A. Mir, Imran Ashraf, Michelle L. MattesonKome, Matthew L. Bechtold); 'Medicine, University of California,

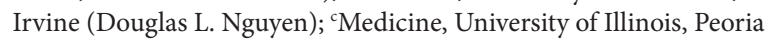
(Srinivas R. Puli), USA

\section{Conflict of Interest: None}

Correspondence to: Matthew L. Bechtold, MD, FACP, FASGE, FACG, AGAF, Division of Gastroenterology and Hepatology, CE405, DC 043.00, University of Missouri Health Sciences Center, Five Hospital Drive, Columbia, MO 65212, USA, Tel.: +1 5738821013

Fax: +1 573884 4595, e-mail: bechtoldm@health.missouri.edu

Received 29 May 2016; accepted 01 July 2016; published online 28 July 2016

DOI: http://dx.doi.org/10.20524/aog.2016.0075 colon cancer is 134,490 , potentially resulting in 49,910 deaths [1]. Screening for colon cancer with colonoscopy for early detection of polyps at a precancerous stage is extremely important in preventing these deaths. The death rates from colon cancer declined by on average $2.7 \%$ each year from 2004 to 2013, because of screening and removal of precancerous polyps [1]. However, polypectomies are associated with complications such as postpolypectomy bleeding, with the rate of bleeding varying from 0.4$10.2 \%$ [2-7]. Bleeding may occur immediately after polypectomy, usually being treated at that time, or it could be delayed. In the latter case, it may be more serious and require a second intervention. The incidence of delayed post-polypectomy bleeding ranges between $0.6-1.2 \%$ [8,9]. Multiple factors have been associated with an increased risk of post-polypectomy bleeding, including polyp size $>10 \mathrm{~mm}$, location (right colon), shape (pedunculated polyps have a higher risk of bleeding compared to sessile), body mass index, number of polyps removed, endoscopist's experience, pathology of polyps removed, and immediate post-polypectomy bleeding [8-10]. The use of aspirin and non-steroid antiinflammatory drugs has not been associated with an increased risk of post-polypectomy bleeding [11]. Attempts to reduce 
the risk of post-polypectomy bleeding using various methods of prophylaxis have been described in multiple case series, retrospective, prospective, and a few randomized controlled studies. Among these methods, prophylactic clipping before or after polypectomy remains controversial, with conflicting results reported in different studies. Thus, this meta-analysis evaluated the role of prophylactic clipping in post-polypectomy bleeding.

\section{Materials and methods}

A systematic and comprehensive literature search of Embase, Scopus, MEDLINE/PubMed, CINAHL, Cochrane databases, and recent abstracts (between 2010 and 2016) from major American meetings (Digestive Disease Week and the American College of Gastroenterology) were searched in April 2016. The references included in all articles were also searched. Search terms used were "prophylactic clip" and "post-polypectomy bleeding". Two reviewers (CB and FM) independently reviewed all abstracts to be included in the study. A third reviewer (MLB) confirmed these results and mutual agreement was necessary in cases of discrepancy or disagreement. All studies in which clipping was the only prophylactic measure used were included. Studies that combined clipping with other measures, such as epinephrine injection or thermal coagulation, were excluded. Studies that had no control group were also excluded. The meta-analysis was conducted using the odds ratio (OR) with the DerSimonian and Laird (random effects) model examining post-polypectomy bleeding with or without a prophylactic clip. Three groups were analyzed: all studies, all peer-reviewed studies with abstracts excluded, and randomized controlled trials (RCTs). In addition, subgroup analysis was performed of those studies with prophylactic clipping performed after polypectomy. The $\mathrm{I}^{2}$ measure of inconsistency $\left(\mathrm{P}<0.1\right.$ or $\mathrm{I}^{2}>50 \%$ was significant) was utilized to measure heterogeneity. If statistically significant heterogeneity was observed, a sensitivity analysis was performed, with the extraction of certain studies until heterogeneity was achieved. RevMan 5.3 (Review Manager, Version 5.3, Copenhagen: The Nordic Cochrane Center, The Cochrane Collaboration, 2012) was used for statistical analysis. Quality assessment of the included studies was performed using the Cochrane's Collaboration Risk of Bias Tool [12-14]. A GRADE was assigned to each outcome based on the quality of evidence. This GRADE is described as very low, low, moderate, or high quality based on variable quality parameters [12-14].

\section{Results}

A total of 530 potential articles and abstracts were identified, from which 35 appropriate articles were reviewed. Once the comprehensive search was completed, 12 studies were included in the final analysis, including four RCTs, with the rest being retrospective [15-26] (Fig. 1). The characteristics of the 12 studies included are summarized in Table 1. In these studies, 13,009 patients were identified (although one study [25] did not report the number of patients) comprising 18,416 polypectomies. The mean age ranged from 61.3-67.4 years (excluding four abstract studies with no available information about patients' demographics). Nearly all studies utilized prophylactic clipping after polypectomy, while one study used clips on large pedunculated polyps prior to polypectomy [20] and one study used a combination of clipping before and after polypectomy [22]. A majority of studies used clips on all sizes of polyps, while a few studies used prophylactic clipping on only large polyps, such as $>5 \mathrm{~mm}$ [18], $>1 \mathrm{~cm}[20]$, or $>2 \mathrm{~cm}[15-17,19,22]$. The quality of the studies ranged from low to moderate to high quality (Table 2).

\section{All studies}

All 12 studies evaluated the use of prophylactic clipping in post-polypectomy bleeding ( $\mathrm{n}=18,415$ polypectomies) [15-26]. Post-polypectomy bleeding was noted in 171 of 18,416 (0.9\%) of all polypectomies. Post-polypectomy bleeding was found in 68 of 4175 (1.6\%) polypectomies with prophylactic clipping and 103 of $14,241(0.7 \%)$ polypectomies with no prophylactic clipping. On pooled analysis, no statistically significant difference was observed between prophylactic clipping versus no prophylactic clipping for post-polypectomy bleeding (OR 1.49; 95\% CI: 0.56-4.00; $\mathrm{P}=0.42$ ) (Fig. 2). Significant heterogeneity was noted in this analysis $\left(\mathrm{I}^{2}=86 \%, \mathrm{P}<0.01\right)$. Based on this heterogeneity, a sensitivity analysis was performed and revealed similar results when two studies were excluded $[15,23]$ with no significant heterogeneity (OR 1.24; 95\% CI: 0.69-2.22; $\mathrm{P}=0.48 ; \mathrm{I}^{2}=35 \%, \mathrm{P}=0.13$ ).

\section{All peer-reviewed studies (abstracts excluded)}

Eight studies [15-22] were published in journals requiring extensive peer review while four were abstract publications [23-26] and were not peer-reviewed. In these peer-reviewed studies, post-polypectomy bleeding occurred in 121 polypectomies when abstracts were excluded. Of the remaining peer-reviewed studies, post-polypectomy bleeding was discovered in 50 of 3594 (1.4\%) with prophylactic clipping

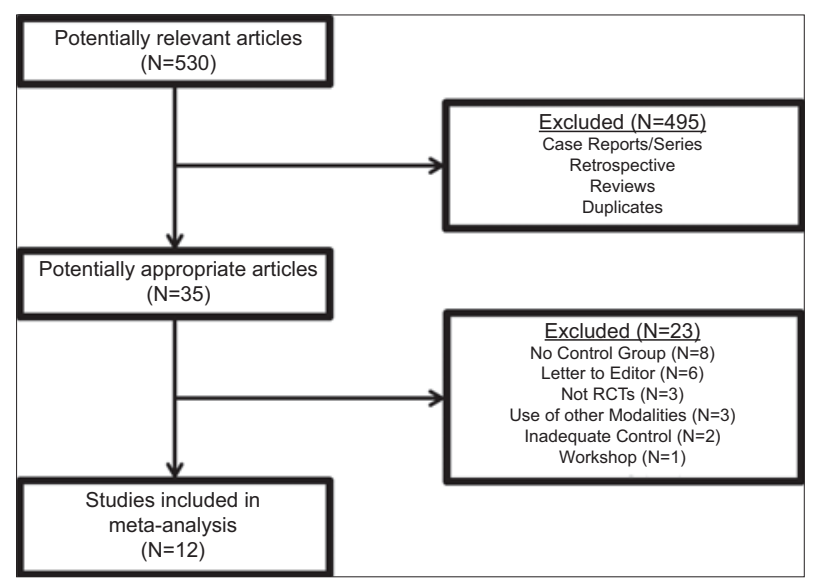

Figure 1 Details of article search and identification 
Table 1 Characteristics of the studies included in the meta-analysis

\begin{tabular}{|c|c|c|c|c|c|c|c|c|}
\hline Author & Type of study & Country & Year & $\begin{array}{l}\text { Number of } \\
\text { patients/ } \\
\text { polypectomies }\end{array}$ & Demographics & Groups & $\begin{array}{l}\text { Number of } \\
\text { polypectomies } \\
\text { per group }\end{array}$ & Bleeding \\
\hline Mastumoto et al [21] & $\begin{array}{l}\text { Randomized } \\
\text { controlled trial }\end{array}$ & Japan & 2016 & $\begin{array}{l}1499 \text { patients } \\
3365 \text { polypectomies }\end{array}$ & $\begin{array}{l}\text { M } 1047 \\
\text { F } 452 \\
\text { Median age } 65-66^{*}\end{array}$ & $\begin{array}{l}\text { Endoclip } \\
\text { No Endoclip }\end{array}$ & $\begin{array}{l}1636 \\
1729\end{array}$ & $\begin{array}{l}18 \\
15\end{array}$ \\
\hline Dokoshi et al [19] & $\begin{array}{l}\text { Randomized } \\
\text { controlled trial }\end{array}$ & Japan & 2015 & $\begin{array}{l}156 \text { patients } \\
288 \text { polypectomies }\end{array}$ & $\begin{array}{l}\text { M } 208 \\
\text { F } 80 \\
\text { Mean age } 67.4\end{array}$ & $\begin{array}{l}\text { Endoclip } \\
\text { No Endoclip }\end{array}$ & $\begin{array}{l}154 \\
134\end{array}$ & $\begin{array}{l}4 \\
3\end{array}$ \\
\hline $\begin{array}{l}\text { Berg et al [23] } \\
\text { (Abstract) }\end{array}$ & Retrospective & United States & 2015 & $\begin{array}{l}7320 \text { patients } \\
7320 \text { polypectomies }\end{array}$ & N/A & $\begin{array}{l}\text { Endoclip } \\
\text { No Endoclip }\end{array}$ & $\begin{array}{l}347 \\
6976\end{array}$ & $\begin{array}{l}14 \\
18\end{array}$ \\
\hline $\begin{array}{l}\text { Lim et al [25] } \\
\text { (Abstract) }\end{array}$ & Retrospective & United States & 2015 & 62 polypectomies & N/A & $\begin{array}{l}\text { Endoclip } \\
\text { No Endoclip }\end{array}$ & $\begin{array}{l}40 \\
22\end{array}$ & $\begin{array}{l}1 \\
2\end{array}$ \\
\hline $\begin{array}{l}\text { Marsano et al [26] } \\
\text { (Abstract) }\end{array}$ & Retrospective & United States & 2014 & $\begin{array}{l}800 \text { patients } \\
2268 \text { polypectomies }\end{array}$ & N/A & $\begin{array}{l}\text { Endoclip } \\
\text { No Endoclip }\end{array}$ & $\begin{array}{c}60 \\
2208\end{array}$ & $\begin{array}{c}1 \\
10\end{array}$ \\
\hline $\begin{array}{l}\text { Vennelaganti } \\
\text { et al [24](Abstract) }\end{array}$ & Retrospective & United States & 2014 & $\begin{array}{l}696 \text { patients } \\
991 \text { polypectomies }\end{array}$ & N/A & $\begin{array}{l}\text { Endoclip } \\
\text { No Endoclip }\end{array}$ & $\begin{array}{l}134 \\
857\end{array}$ & $\begin{array}{l}2 \\
3\end{array}$ \\
\hline Feagins et al [17] & Retrospective & United States & 2014 & $\begin{array}{l}368 \text { patients } \\
1311 \text { polypectomies }\end{array}$ & $\begin{array}{l}\text { M } 364 \\
\text { F } 4 \\
\text { Mean age } 63.7-64.9^{*}\end{array}$ & $\begin{array}{l}\text { Endoclip } \\
\text { No Endoclip }\end{array}$ & $\begin{array}{l}236 \\
610\end{array}$ & $\begin{array}{l}3 \\
1\end{array}$ \\
\hline Liaquat et al [15] & Retrospective & United States & 2013 & $\begin{array}{l}463 \text { patients } \\
524 \text { polypectomies }\end{array}$ & $\begin{array}{l}\text { M } 250 \\
\text { F } 213 \\
\text { Mean age } 67.1\end{array}$ & $\begin{array}{l}\text { Endoclip } \\
\text { No Endoclip }\end{array}$ & $\begin{array}{l}277 \\
247\end{array}$ & $\begin{array}{c}7 \\
24\end{array}$ \\
\hline Mastumoto et al [16] & Retrospective & Japan & 2012 & $\begin{array}{l}375 \text { patients } \\
403 \text { polypectomies }\end{array}$ & $\begin{array}{l}\text { M } 240 \\
\text { F } 135 \\
\text { Mean age } 63.3\end{array}$ & $\begin{array}{l}\text { Endoclip } \\
\text { No Endoclip }\end{array}$ & $\begin{array}{l}174 \\
229\end{array}$ & $\begin{array}{c}3 \\
14\end{array}$ \\
\hline Quintanilla et al [20] & $\begin{array}{l}\text { Randomized } \\
\text { controlled trial }\end{array}$ & Spain & 2012 & $\begin{array}{l}98 \text { patients } \\
105 \text { polypectomies }\end{array}$ & $\begin{array}{l}\text { M } 73 \\
\text { F } 32 \\
\text { Mean age 64.05-65.55* }\end{array}$ & $\begin{array}{l}\text { Endoclip } \\
\text { No Endoclip }\end{array}$ & $\begin{array}{l}66 \\
39\end{array}$ & $\begin{array}{l}1 \\
0\end{array}$ \\
\hline Shioji et al [18] & $\begin{array}{l}\text { Randomized } \\
\text { controlled trial }\end{array}$ & Japan & 2003 & $\begin{array}{l}323 \text { patients } \\
413 \text { polypectomies }\end{array}$ & $\begin{array}{l}\text { M } 248 \\
\text { F } 75 \\
\text { Mean age } 63-63^{*}\end{array}$ & $\begin{array}{l}\text { Endoclip } \\
\text { No Endoclip }\end{array}$ & $\begin{array}{l}205 \\
208\end{array}$ & $\begin{array}{l}2 \\
2\end{array}$ \\
\hline Fukata et al [22] & Retrospective & Japan & 2002 & $\begin{array}{l}911 \text { patients } \\
1828 \text { polypectomies }\end{array}$ & $\begin{array}{l}\text { M } 618 \\
\text { F } 293 \\
\text { Mean age } 61.3-62.7^{*}\end{array}$ & $\begin{array}{l}\text { Endoclip } \\
\text { No Endoclip }\end{array}$ & $\begin{array}{l}846 \\
982\end{array}$ & $\begin{array}{l}12 \\
12\end{array}$ \\
\hline
\end{tabular}

${ }^{*}$ Median or mean age represents the median or mean age of each group (control and variable)

\begin{tabular}{|c|c|c|c|c|c|c|c|c|c|c|}
\hline \multirow[b]{2}{*}{ Study or Subgroup } & \multicolumn{2}{|c|}{ Proplyylactic Clip } & \multicolumn{2}{|c|}{ No Prophylactic Clip } & \multirow[b]{2}{*}{ Weight } & \multirow{2}{*}{$\begin{array}{c}\text { Odds Ratio } \\
\text { M-H, Random, } 95 \% \mathrm{CI}\end{array}$} & \multirow{2}{*}{\multicolumn{4}{|c|}{$\begin{array}{l}\text { Odds Ratio } \\
\text { M.H, Random, } 95 \% \mathrm{Cl}\end{array}$}} \\
\hline & Events & Total & Events & Total & & & & & & \\
\hline Berg - 2015 & 14 & 347 & 18 & 6976 & $10.3 \%$ & $16.25[8.01,32.96]$ & & & $\longrightarrow$ & \\
\hline Dokoshi - 2015 & 4 & 154 & 3 & 134 & $8.7 \%$ & $1.16[0.26,5.30]$ & & & & \\
\hline Feagins - 2014 & 3 & 236 & 1 & 610 & $6.9 \%$ & $7.84[0.81,75.76]$ & & & & \\
\hline Fukata- 2002 & 12 & 846 & 12 & 982 & $10.2 \%$ & $1.16[0.52,2.60]$ & & & & \\
\hline Liaquat - 2013 & 7 & 277 & 24 & 247 & $10.1 \%$ & $0.24[0.10,0.57]$ & & & & \\
\hline Lim- 2015 & 1 & 40 & 2 & 22 & $6.5 \%$ & $0.26[0.02,3.00]$ & & & & \\
\hline Marsano- 2014 & 1 & 60 & 10 & 2208 & $7.4 \%$ & $3.73[0.47,29.58]$ & & & & \\
\hline Matsumoto - 2012 & 3 & 174 & 14 & 229 & $9.3 \%$ & $0.27[0.08,0.95]$ & & & & \\
\hline Matsumoto- 2016 & 18 & 1636 & 15 & 1729 & $10.4 \%$ & $1.27[0.64,2.53]$ & & & & \\
\hline Quintanilla - 2012 & 1 & 66 & 0 & 39 & $5.0 \%$ & $1.81[0.07,45.50]$ & & & & \\
\hline Shioji - 2003 & 2 & 205 & 2 & 208 & $7.6 \%$ & $1.01[0.14,7.27]$ & & & & \\
\hline Vennelaganti - 2014 & 2 & 134 & 2 & 857 & $7.6 \%$ & $6.48[0.90,46.38]$ & & & & \\
\hline Total $(95 \% \mathrm{Cl})$ & & 4175 & & 14241 & $100.0 \%$ & $1.49[0.56,4.00]$ & & & & \\
\hline Total events & 68 & & 103 & & & & & & & \\
\hline \multicolumn{7}{|c|}{$\begin{array}{l}\text { Heterogeneity, } \text { Tau }^{2}=2.31 ; \mathrm{Chi}^{2}=80.37, \mathrm{df}=11(P<0.00001) ; \mathrm{I}^{2}=86 \% \\
\text { Test for overall effect: } Z=0.80(P=0.42)\end{array}$} & 0.01 & ${ }_{\text {Favors Clip }}^{0.1}$ & ${ }^{1}{ }_{\text {Favors No Clip }}^{10}$ & $\overrightarrow{100}$ \\
\hline
\end{tabular}

Figure 2 Forest plot showing the comparison between prophylactic clipping and no prophylactic clipping for polypectomies in all studies 
and 71 of $4178(1.7 \%)$ with no prophylactic clipping. No statistically significant difference was noted between the two groups for post-polypectomy bleeding when abstracts were excluded (OR 0.84; 95\% CI: 0.42-1.69; $\mathrm{P}=0.63$ ). Heterogeneity was statistically significant $\left(\mathrm{I}^{2}=60 \%, \mathrm{P}=0.01\right)$ (Fig. 3). On sensitivity analysis, when one study was removed [15], the results were similar with no significant heterogeneity (OR 1.07; 95\% CI: 0.61-1.88; $\mathrm{P}=0.8 ; \mathrm{I}^{2}=25 \%, \mathrm{P}=0.24$ ).

\section{RCTs}

Four RCTs (4171 polypectomies in 2076 patients) were analyzed separately [18-21]. In these RCTs, 45 episodes of post-polypectomy bleeding were noted. Delayed bleeding was noted in 25 of 2061 (1.2\%) polypectomies in the prophylactic clip group and 20 of $2110(0.9 \%)$ polypectomies in the no prophylactic clip group. In pooled analysis, no statistically significant difference was noted in RCTs between prophylactic clipping versus no prophylactic clipping for post-polypectomy bleeding (OR 1.24; 95\% CI: 0.69-2.24; $\mathrm{P}=0.47$ ) (Fig. 4). No publication bias or heterogeneity was noted $\left(\mathrm{I}^{2}=0 \%, \mathrm{P}=0.99\right)$.

\section{Subgroup analysis}

The use of prophylactic clipping only after polypectomy was evaluated by 10 studies (16,483 polypectomies) [15-19,21,23-26]. Two studies were excluded from this subgroup analysis because of clipping before the polypectomy $[20,22]$. In this subgroup

Table 2 Assessment of quality of included studies using Cochrane's collaboration risk of bias tool

\begin{tabular}{|c|c|c|c|c|c|c|c|c|c|}
\hline Study & Study design & $\begin{array}{l}\text { Random } \\
\text { sequence } \\
\text { generation }\end{array}$ & $\begin{array}{l}\text { Allocation } \\
\text { concealment }\end{array}$ & Blinding & $\begin{array}{l}\text { Blinding } \\
\text { outcome } \\
\text { assessment }\end{array}$ & $\begin{array}{l}\text { Incomplete } \\
\text { outcome } \\
\text { data }\end{array}$ & $\begin{array}{l}\text { Selective } \\
\text { reporting }\end{array}$ & $\begin{array}{l}\text { Other } \\
\text { bias }\end{array}$ & $\begin{array}{l}\text { Quality } \\
\text { assessment }\end{array}$ \\
\hline Dokoshi et al [19] 2015 & RCT & Adequate & Adequate & Single-blinded & Adequate & None & None & None & High \\
\hline Quintanilla et al [20] 2012 & RCT & Adequate & Adequate & Single-blinded & Adequate & None & None & None & High \\
\hline Shioji et al [18] 2003 & RCT & Inadequate & Adequate & Single-blinded & Adequate & None & None & None & High \\
\hline Matsumoto et al [21] 2016 & $\mathrm{RCT}$ & Adequate & Adequate & Single-blinded & Adequate & None & None & Mild & Moderate-to-high \\
\hline Feagins et al [17] 2014 & Retrospective & None & None & None & None & None & None & None & Moderate \\
\hline Liaquat et al [15] 2013 & Retrospective & None & None & None & None & None & None & None & Moderate \\
\hline Matsumoto et al [16] 2012 & Retrospective & None & None & None & None & None & None & None & Moderate \\
\hline Fukata et al [22] 2002 & Retrospective & None & None & None & None & None & None & None & Moderate \\
\hline $\begin{array}{l}\text { Berg et al [23] } \\
\text { 2015-Abstract }\end{array}$ & Retrospective & None & None & None & None & None & None & None & Low-to-moderate \\
\hline $\begin{array}{l}\text { Lim et al [25] } \\
\text { 2015-Abstract }\end{array}$ & Retrospective & None & None & None & None & None & None & None & Low-to-moderate \\
\hline $\begin{array}{l}\text { Vennelaganti et al [24] } \\
\text { 2014-Abstract }\end{array}$ & Retrospective & None & None & None & None & None & None & None & Low-to-moderate \\
\hline $\begin{array}{l}\text { Marsano et al [26] } \\
\text { 2014-Abstract }\end{array}$ & Retrospective & None & None & None & None & None & None & None & Low-to-moderate \\
\hline
\end{tabular}

RCT, randomized controlled trial

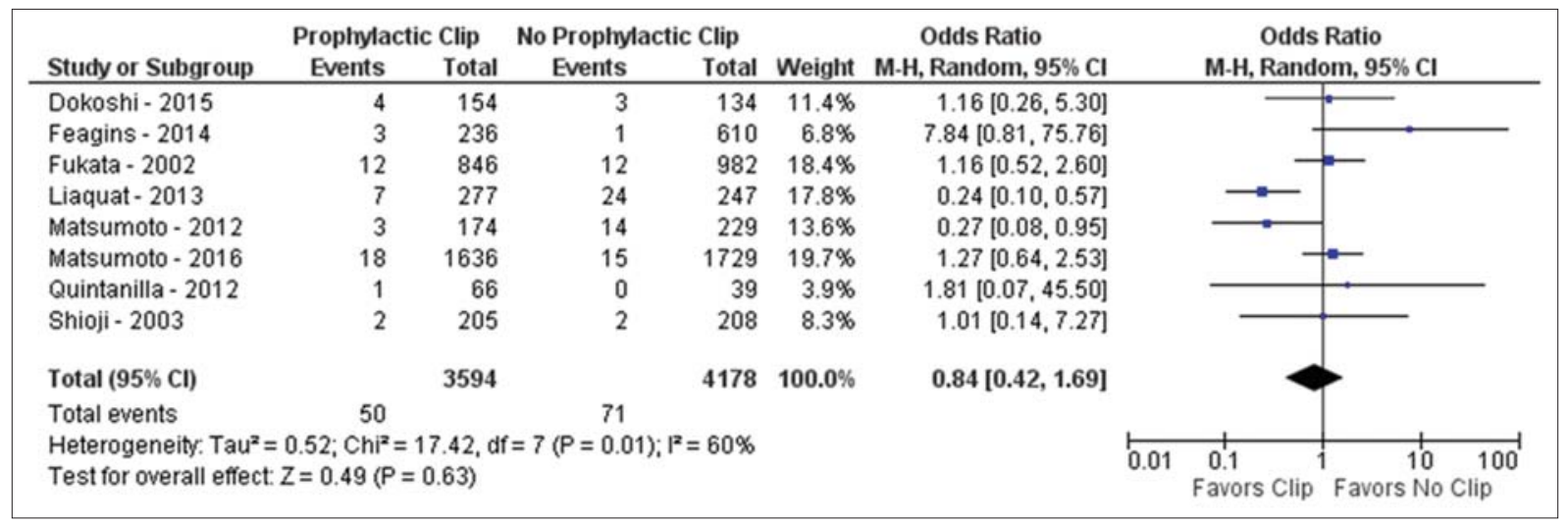

Figure 3 Forest plot showing the comparison between prophylactic clipping and no prophylactic clipping for polypectomies in only peer-reviewed studies (no abstracts) 


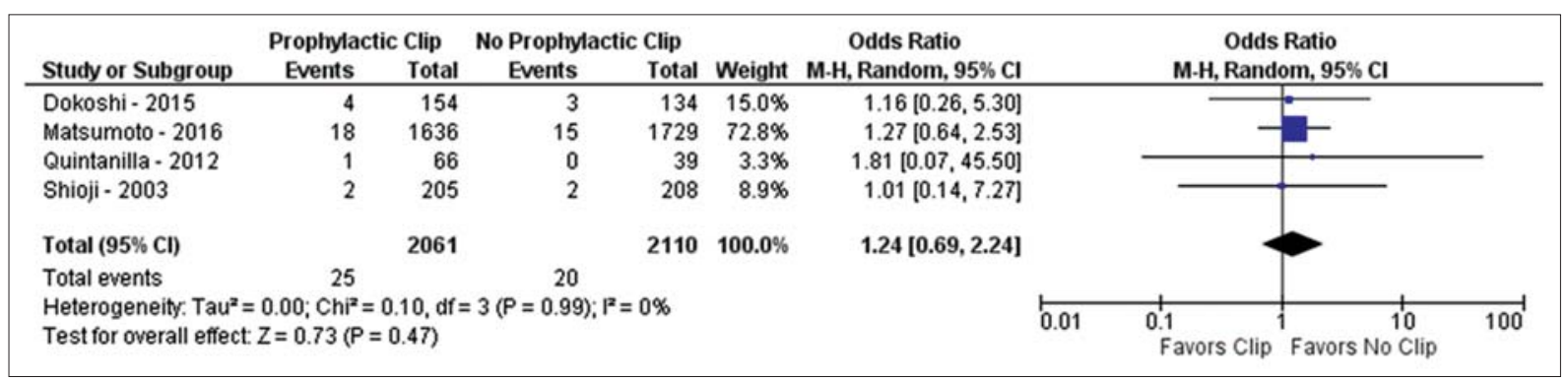

Figure 4 Forest plot showing the comparison between prophylactic clipping and no prophylactic clipping for polypectomies in only randomized controlled trials

analysis, prophylactic clipping demonstrated no difference from no clipping for post-polypectomy bleeding (OR 1.53; 95\% CI: $0.46-5.03 ; \mathrm{P}=0.49$ ).

\section{Discussion}

Polypectomy during colonoscopy is considered safe and well tolerated by patients. However, since post-polypectomy bleeding has a significant impact on both patients and healthcare costs, it would be desirable to decrease its incidence. Endoscopists have used clips in an attempt to decrease the rate of post-polypectomy bleeding, although the overall benefit of this method remains controversial. Some retrospective studies have demonstrated a benefit from prophylactic clip application to decrease the risk of post-polypectomy bleeding. Liaquat et al found that the delayed hemorrhage rate was $9.7 \%$ in the nonclipping group versus $1.8 \%$ in the clipping group; however, all endoscopic mucosal resections were performed on lesions larger than $2 \mathrm{~cm}$, and multivariate analysis showed that polyp size was associated with delayed bleeding [15]. Mastumoto et al showed that delayed bleeding after endoscopic resection of colorectal lesions larger than $2 \mathrm{~cm}$ was more prevalent in patients who did not undergo prophylactic clip placement [16]. Feagins et al reported no benefit from prophylactic clipping, with bleeding rates of $1.6 \%$ in the prophylactic hemoclipping group and $0.5 \%$ in the matched control group, a difference without statistical significance [17].

In contrast, all RCTs to-date have failed to show a beneficial effect of prophylactic clipping. In 2003, Shioji et al evaluated 413 post-polypectomy ulcers treated by the endoscopic mucosal resection technique, with a mean polyp size of $7.8 \mathrm{~mm}$, and found no decrease in delayed bleeding after polypectomy with prophylactic clip placement [18]. In another RCT, Dokoshi et al showed that there was no difference in bleeding between patients who received clips and those who did not [19]. Although the rate of bleeding was significantly higher in lesions $2 \mathrm{~cm}$ or larger in size, there was no significant difference in the bleeding rate between the clipping and non-clipping groups, regardless of the size of the lesions [19]. In 2012, another RCT showed no beneficial effects of clipping for preventing delayed bleeding [20]. However, this study was somewhat different and included only pedunculated polyps larger than $10 \mathrm{~mm}$, in which prophylactic clipping was performed before the endoscopic resection, and the study was suspended early because of the increase risk of morbidity in the clipping group, with high rates of mucosal burns and perforation exceeding that of post-polypectomy bleeding [20]. In all three of these RCTs, patients on anticoagulation were asked to discontinue their medications up to 7 days prior to the procedure, according to the guidelines. In the most recent RCT, Mastumoto et al demonstrated the non-inferiority of no clipping by analyzing 3365 polyps less than $2 \mathrm{~cm}$ in diameter [21]. The rates of postpolypectomy bleeding were $1.1 \%$ in the clipping group versus $0.9 \%$ in the non-clipping group, with a difference of $-0.2 \%$ (95\% CI: -0.96-0.53) [21]. In this RCT, polypectomies were performed using either endoscopic mucosal resection or snare polypectomies with electrosurgical current. Antithrombotic medication, including antiplatelet agents, was interrupted before the procedure in accordance with the relevant guidelines. The investigators' univariate analysis revealed that polyp size, additional coagulation, and the endoscopist's experience were risk factors for post-polypectomy bleeding; however, multivariate analysis showed that only additional coagulation for oozing vessels after resection and polyp size were significant risk factors.

Our meta-analysis, considering all polypectomies performed by endoscopic mucosal resection or snare polypectomy, when all polyp sizes were pooled together, found that prophylactic clip placement was not associated with any difference in post-polypectomy bleeding. This result was consistent across multiple analyses of all studies in the literature, of only peerreviewed studies, and of only RCTs. Given the consistency of results across all levels of the literature, prophylactic clipping does not appear to be beneficial in preventing postpolypectomy bleeding for all polyps.

All studies, including meta-analyses, have strengths and weaknesses. In this meta-analysis, the strengths include the following. First, an extensive three-stage literature search was performed of the databases most commonly used in metaanalyses. Second, studies in various locations were analyzed, including Japan, the United States, and Spain. Third, three separate analyses were performed, based on the level of evidence in the literature: all studies, only peer-reviewed studies, and only RCTs. This validated the same result across the levels of evidence. However, the limitations of this study must also be acknowledged. First, heterogeneity was considered significant in two of the three outcomes (all studies and only peer-reviewed studies). Based on this, a random effects model 
was used for analysis and sensitivity analyses were performed on these two outcomes, showing no difference in the results. Furthermore, when RCTs were analyzed no heterogeneity was observed, with similar results to the other two outcomes. Second, anticoagulation/antiplatelet therapy was interrupted in accordance with the guidelines. Therefore, the benefit of prophylactic clipping was not assessed in patients who were taking anticoagulation or antiplatelet medications and the results in those patients might be different. Some authors reported a benefit from clipping in patients on antithrombotic drugs [27-29]. Borodyansky et al suggested that polyps larger than $2 \mathrm{~cm}$ in patients not receiving antithrombotic therapy and larger than $1 \mathrm{~cm}$ in patients receiving antithrombotic treatment be clipped [29]. Further studies of prophylactic clipping should be performed that include patients on these medications. Third, despite the pooling of all available data, the rate of post-polypectomy bleeding is very low and may be subject to type II statistical bias with a lack of overall power. This may be seen from the large confidence intervals. However, this meta-analysis included 171 cases of post-polypectomy bleeding in 18,416 polypectomies, which represent all the available literature. In addition, the confidence intervals for the peer-reviewed studies and RCTs were not large, suggesting that type II error had only a minimal effect. Fourth, the method of closure of the post-polypectomy defect was not fully analyzed, since the closure method was not consistently reported across all the studies. Further studies are necessary to evaluate the effect of closure method on post-polypectomy bleeding. Fifth, given the limited number of studies performing prophylactic clipping on only pedunculated polyps, further studies are required for analysis of the use of prophylactic clipping in these polyps. Finally, all polypectomies were included in this metaanalysis, with no distinction between large polyps $(>2 \mathrm{~cm})$ and other smaller polyps. Since the majority of research articles did not discriminate between large and small polyps, reporting a fraction of the data from those that did would have introduced bias. In addition, in those studies from which we were able to extract data specifically for large polyps $(>2 \mathrm{~cm})[15-17,19,22]$, prophylactic clipping demonstrated a trend toward less post-polypectomy bleeding, but the difference did not reach statistical significance (OR 0.42; 95\% CI: 0.14-1.23; $\mathrm{P}=0.11$ ). However, this pooling of data may not be accurate given that one of the studies [17] had zero post-polypectomy bleeding in both groups, resulting in a non-estimable analysis. Furthermore, these five studies used different techniques for prophylactic clipping, with one study [22] using clips before and after polypectomy, while the others used clips after polypectomy. Therefore, prophylactic clipping, although not beneficial across all polypectomies, may or may not be beneficial in the treatment of large polyps. Further studies are required to elucidate this matter.

In conclusion, prophylactic clipping with polypectomy does not appear to be beneficial in preventing postpolypectomy bleeding in all polyps. Given the increased procedure-related costs (higher in the United States than in other countries) and the time required to perform a procedure with prophylactic clipping, without any obvious benefit, prophylactic clipping should not be routinely used during

\section{Summary Box}

\section{What is already known:}

- Post-polypectomy bleeding is a complication endoscopists' would prefer to prevent

- Prophylactic clipping before and after polypectomy has become widely used, although the literature is lacking regarding the efficacy of such a practice

- Prophylactic clipping before or after polypectomy remains controversial

\section{What the new findings are:}

- Prophylactic clipping does not appear to affect the rates of post-polypectomy bleeding for all polypectomies

- Given the cost and lack of efficacy, prophylactic clipping should not be routinely used in all polypectomies

- In polyps $>2 \mathrm{~cm}$, prophylactic clipping may or may not be beneficial in preventing post-polypectomy bleeding and further studies are required to fully assess this population

colonoscopy. Further studies are required to assess the benefit of prophylactic clipping after polypectomy in patients who are taking anticoagulant or antiplatelet medications and in those with large polyps $(>2 \mathrm{~cm})$.

\section{References}

1. NIH. SEER Stat Fact Sheets: Colon and Rectum Cancer, 2016. Available at: http://seer.cancer.gov/statfacts/html/colorect.html.

2. Rosen L, Bub DS, Reed JF $3^{\text {rd }}$, Nastasee SA. Hemorrhage following colonoscopic polypectomy. Dis Colon Rectum 1993;36:1126-1131.

3. Dobrowolski S, Dobosz M, Babicki A, Głowacki J, Nałecz A. Blood supply of colorectal polyps correlates with risk of bleeding after colonoscopic polypectomy. Gastrointest Endosc 2006;63:1004-1009.

4. Sawhney MS, Salfiti N, Nelson DB, Lederle FA, Bond JH. Risk factors for severe delayed postpolypectomy bleeding. Endoscopy 2008; $40: 115-119$.

5. Singaram C, Torbey CF, Jacoby RF. Delayed postpolypectomy bleeding. Am J Gastroenterol 1995;90:146-147.

6. Choung BS, Kim SH, Ahn DS, et al. Incidence and risk factors of delayed postpolypectomy bleeding: a retrospective cohort study. J Clin Gastroenterol 2014;48:784-789.

7. Wu XR, Church JM, Jarrar A, Liang J, Kalady MF. Risk factors for delayed postpolypectomy bleeding: how to minimize your patients' risk. Int J Colorectal Dis 2013;28:1127-1134.

8. Zhang Q, An Sl, Chen Zy, et al. Assessment of risk factors for delayed colonic post-polypectomy hemorrhage: a study of 15553 polypectomies from 2005 to 2013. PLoS One 2014;9:e108290. 
9. Kwon MJ, Kim YS, Bae SI, et al. Risk factors for delayed postpolypectomy bleeding. Intest Res 2015;13:160-165.

10. Bae GH, Jung JT, Kwon JG, et al. Risk factors of delayed bleeding after colonoscopic polypectomy: case-control study. Korean $J$ Gastroenterol 2012;59:423-427.

11. Shalman D, Gerson LB. Systematic review with meta-analysis: the risk of gastrointestinal haemorrhage post-polypectomy in patients receiving anti-platelet, anti-coagulant and/or thienopyridine medications. Aliment Pharmacol Ther 2015;42:949-956.

12. Higgins JPT, Green S. Cochrane handbook for systematic reviews of interventions. The Cochrane Collaboration 2011. http:// handbook.cochrane.org.

13. Guyatt GH, Oxman AD, Vist GE, et al; GRADE Working Group. GRADE: an emerging consensus on rating quality of evidence and strength of recommendations. BMJ 2008;336:924-926.

14. GRADE working group. Criteria for applying or using GRADE. http://www.gradeworkinggroup.org/intro.htm\#criteria.

15. Liaquat H, Rohn E, Rex DK. Prophylactic clip closure reduced the risk of delayed postpolypectomy hemorrhage: experience in 277 clipped large sessile or flat colorectal lesions and 247 control lesions. Gastrointest Endosc 2013;77:401-407.

16. Matsumoto M, Fukunaga S, Saito Y, et al. Risk factors for delayed bleeding after endoscopic resection for large colorectal tumors. Jpn J Clin Oncol 2012;42:1028-1034.

17. Feagins LA, Nguyen AD, Iqbal R, Spechler SJ. The prophylactic placement of hemoclips to prevent delayed post-polypectomy bleeding: an unnecessary practice? A case control study. Dig Dis Sci 2014; 59:823-828.

18. Shioji K, Suzuki Y, Kobayashi M, et al. Prophylactic clip application does not decrease delayed bleeding after colonoscopic polypectomy. Gastrointest Endosc 2003;57:691-694.

19. Dokoshi T, Fujiya M, Tanaka K, et al. A randomized study on the effectiveness of prophylactic clipping during endoscopic resection of colon polyps for the prevention of delayed bleeding. Biomed Res Int 2015;2015:490272.

20. Quintanilla E, Castro JL, Rábago LR, et al. Is the use of prophylactic hemoclips in the endoscopic resection of large pedunculated polyps useful? A prospective and randomized study. J Interv Gastroenterol 2012;2:183-188.

21. Matsumoto M, Kato M, Oba K, et al. Multicenter randomized controlled study to assess the effect of prophylactic clipping on post-polypectomy delayed bleeding. Dig Endosc 2016 [Epub ahead of print].

22. Fukata $M$, Kijima $H$, Sanjo A, Sugisaka H, Inoue T, Takagi I. Prophylactic clipping may not eliminate delayed hemorrhage in colonoscopic polypectomies. Jikeikai Med J 2002;49:133-142.

23. Berg ZM, Love WT, Gurudu S, et al. Delayed post-polypectomy bleeding is not prevented by prophylactic hemoclips: experience at a tertiary academic medical center. Gastrointest Endosc 2015;81:AB305. (abstract)

24. Vennelaganti S, Siddique S, Romana BS, et al. Predictive factors for prophylactic clip placement after snare polypectomy. Gastroenterology 2015;148:S595-S596. (abstract)

25. Lim B, Eskandari A, Yaramada P, Chaya C. Effect of prophylactic endoclips on prevention of delayed post-endoscopic mucosal resection bleed. Am J Gastroenterol 2015;110:S684. (abstract)

26. Marsano J, Antony A, Tzimas D, Pochapin M, Goodman A, Gross S. The role of prophylactic hemoclips to prevent delayed post-polypectomy bleeding in patients on chronic anticoagulation: a large university-based experience. Am $J$ Gastroenterol 2014;109:S206. (abstract)

27. Katsinelos P, Fasoulas K, Chatzimavroudis G, et al. Prophylactic clip application before endoscopic resection of large pedunculated colorectal polyps in patients receiving anticoagulation or antiplatelet medications. Surg Laparosc Endosc Percutan Tech 2012;22:e254-e258.

28. Parikh ND, Zanocco K, Keswani RN, Gawron AJ. A costefficacy decision analysis of prophylactic clip placement after endoscopic removal of large polyps. Clin Gastroenterol Hepatol 2013;11:1319-1324.

29. Borodyansky L, Saltzman JR. Fat polyp, thin blood: think clip! Clin Gastroenterol Hepatol 2013;11:1333-1334. 